\title{
Common knowledge and reductionism about shared agency
}

Blomberg, Olle

Published in:

Australasian Journal of Philosophy

DOI:

10.1080/00048402.2015.1055581

Publication date:

2016

Document version

Peer reviewed version

Citation for published version (APA):

Blomberg, O. (2016). Common knowledge and reductionism about shared agency. Australasian Journal of Philosophy, 94(2), 315-326 . https://doi.org/10.1080/00048402.2015.1055581 


\title{
Common knowledge and reductionism about shared agency
}

\author{
Olle Blomberg \\ olle.blomberg@gmail
}

June 24, 2015

\begin{abstract}
This is a preprint of an article whose final and definitive form will be published in the Australasian Journal of Philosophy 2015. The Australasian Journal of Philosophy is available online at: http://www.tandf.co.uk/journals/.
\end{abstract}

\begin{abstract}
Most reductionist accounts of intentional joint action include a condition that it must be common knowledge between participants that they have certain intentions and beliefs that cause and coordinate the joint action. However, this condition has typically simply been taken for granted rather than argued for. The condition is not necessary for ensuring that participants are jointly responsible for the action that each participates in, nor for ensuring that each treats the others as partners rather than as social tools. It is thus something of a mystery why the condition is so widely accepted. By rejecting three arguments that could potentially support it, I argue that reductionists should get rid of the condition. I show that the first two arguments fail. While the final argument is intuitively compelling, it builds on key premises that are unavailable to the reductionist.
\end{abstract}




\section{Introduction}

What is required for several agents to intentionally act together? According to reductionist accounts, intentional joint action can be understood by exclusive appeal to conceptual resources that are anyway needed for understanding intentional singular action in a social context. An intentional joint action is simply a joint action that is caused and coordinated by an interpersonal structure of ordinary propositional attitudes with certain contents. Using a technical term, we can refer to this structure as the agents' 'shared intention'.

For instance, according to Pettit and Schweikard's reductionist account, several agents are engaged in an intentional joint action only if:

1. they each intend that they enact the [joint] performance;

2. they each intend to do their bit in this performance;

3. they each believe that others intend to do their bit; and

4. they each intend to do their bit because of believing this [that others intend to do their bit].

[Pettit and Schweikard 2006: 23]

For our lifting of the table to be jointly intentional, it isn't sufficient that each intentionally lifts one end of it in the expectation that the other will intentionally lift the other end. A natural first thought then, is that for you and I to intentionally jointly J, each must intend that we J, that we enact a joint performance of some sort (condition 1 above). Of course, each of us must also intend to lift our own end of the table-do our bit of the J-ing-to participate in the joint action (condition 2). Since the reductionist aims to provide an informative non-circular analysis of intentional joint action, the notion of 'joint performance' or of 'our J-ing' that figures in the content of each participant's intentions cannot be the notion of intentional joint action (this will play a crucial role in the arguments that follow). Pettit and Schweikard therefore insist that a joint performance 'can be conceptualized just as a pattern of behavior in which our different efforts combine to effect a certain result.' [ibid.: 29] Similarly, Bratman argues that our J-ing can be conceptualised as, for example, each of us Jing where this is compatible with each doing this 'in ignorance of the other person's activity' [1997a: 52].

Intentional joint action is characterised by at least a minimal form of intentional cooperation. The notion of 'doing one's bit' in conditions 2-4 should therefore be understood (by analyst and participants alike) as a voluntary and uncoerced contribution to the joint performance [Pettit and Schweikard 2006: 22]. Hence, cases where an agent treats another as a social tool rather than as a partner are ruled out by conditions 3 and 4. In Bratman's [1992; 1993] reductionist account, this is achieved by requiring that each participant intends both (i) that they $\mathrm{J}$ 'in accordance with and because of' the other's intention that they J, and (ii) that they J by way of subplans that 'mesh' (see [1992: 331-34]). Agents' sub-plans mesh if they are co-realisable. In the table-lifting case, our sub-plans mesh if we intend to lift at opposite ends of the table, but not if we intend to lift at the same end. Requirement (i) rules out cases in which one participant intends that they J 
in ways that bypass the other's intentional agency, such as in the case where I intend that we drive to Melbourne by way of knocking you unconscious and putting you in the trunk of my car rather than by way of your intention that we drive there. Requirement (ii) rules out cases in which one participant intends to deceive or manipulate the other. For example, suppose that I intend that we drive to Melbourne by taking the inland Hume Highway but I know that you intend that we drive there by taking the coastal Princes Highway. However, I deceive you into thinking that I intend that we take the Princes Highway too, while I actually intend to drive onto the Hume Highway as soon as you fall asleep. I could not rationally intend this if I also had the intention that my and your subplans mesh.

If a joint action is appropriately caused by the intentions and beliefs specified by $1-4$, is it then an intentional joint action? Initially, one might think that the answer is 'yes'. The participants will each treat the others as partners rather than social tools with respect to the joint performance. Due to the required interdependence between the participants' intended contributions, they will also be 'responsible together for an action in which they each participate' [Pettit and Schweikard 2006: 19-22]. After all, each settles whether the whole performance is enacted. Note that this doesn't mean that they are jointly responsible $a s$ a group. The notion of joint responsibility that is relevant here is a distributive notion of each being responsible for the entire joint performance that they each intentionally bring about by doing their bit (see Sverdlik [1987]; Bratman [1997b: 32]). Nevertheless, Pettit and Schweikard's answer is 'no'. The following fifth condition must also be satisfied:

5. they each believe in common that the other clauses hold.

They unpack this common belief or common knowledge condition (henceforth CK-condition) as follows:

The clause stipulates that everything amongst the parties is above board. Take any question that might arise as to whether I am really aware of what is happening, or really aware of our each being aware of what is happening, or really aware of our each being aware of our each being aware of what is happening, and so on. The clause stipulates that we are each disposed to give an affirmative response to such a question; in that sense, we are aware of what is happening, aware of our each being aware of this, and so on in the usual hierarchy of common belief (Lewis 1969).

[Pettit and Schweikard 2006: 23-24]

Most reductionist accounts include such a necessary CK-condition (e.g. [Tuomela and Miller 1988; Cohen and Levesque 1991; Bratman 1992, 1993; Miller 2001; Tollefsen 2005; Alonso 2009]). ${ }^{1}$ However, the condition is typically merely assumed rather than argued for. For instance, Miller submits that 'mutual knowledge is what distinguishes joint action from interdependent action that is

${ }^{1}$ Kutz [2000], Ludwig [2007] and Bratman [2014] present reductionist accounts without a necessary a CK-condition. 
not joint', but never explains why mutual knowledge has this transformative power [2001: 60]. Tollefsen claims that joint attention as well as common knowledge can 'introduce the openness that needs to be present in cases of joint action', but doesn't explain why this openness is needed [2005: 92]. Bratman similarly introduces the CK-condition by simply asserting that 'it seems reasonable to suppose that in shared intention the fact that each has the relevant attitudes is itself out in the open, is public.' [1993: 103] (but see [2014: 57-58]). Note that 'mutual knowledge', 'openness' and talk of attitudes being 'public' are different ways of referring to what I refer to as 'common knowledge'.

In this paper, I argue that reductionists should reject the CK-condition as a necessary condition for intentional joint action as such. In $\S 2$, I present a case in which all conditions except the CK-condition are satisfied according to both Pettit and Schweikard's [2006] account and Bratman's [1993] account. Three arguments for the CK-condition are then considered in $\S 3, \S 4$ and $\S 5$ in light of this case. I reject the first two arguments. While there may be something to the third argument, I argue that it isn't available to the reductionist.

I set aside whether non-reductionists should also reject a necessary CK-condition for two reasons. First, it is not altogether clear whether non-reductionists who include a CK-condition, such as Tuomela [2007], are targeting the same phenomenon as the reductionists. Secondly, non-reductionists have access to argumentative resources that are unavailable to reductionists (but at the cost, of course, of a less parsimonious ontology). Hence, it is not clear whether criticising the three arguments I focus on here suffices for drawing conclusions about nonreductionist accounts.

\section{A joint performance without common knowledge}

Consider this case: Hector and Celia are about to build a block tower. Each intends that they build a block tower, and each intends to do their bit of this joint performance. Pettit and Schweikard's conditions 1 and 2 are thus satisfied. Recall that this does not mean that each intends to do their bit of intentionally jointly building a block tower, but merely that each intends to do their bit of enacting a pattern of behaviour in which their different efforts combine to the effect that the block tower is built. Hector and Celia each believes that the other intends to do their bit, and each believes that the other conceives of the intended bit as a bit of the joint performance (in other words, each believes that the other intends that they build a block tower). Condition 3 is thus satisfied. Furthermore, it is in virtue of believing this that each intends to do their bit: Each intends to do their bit of the joint performance because the other intends to do their bit of it. Hence, condition 4 is also satisfied. Suppose also that each intends that their subplans for building the block tower mesh with the subplans of the other. ${ }^{2}$

These intentions and beliefs appropriately cause Hector and Celia to build the block tower, that is, the attitudes cause them to take turns putting blocks on top

${ }^{2}$ Conditions 1 and 2 of Bratman's [1993] account of shared intention would thus be satisfied. 
of each other so that a block tower is built. ${ }^{3}$ Celia starts by putting down one of her blocks, Hector then puts down a block on hers, and so on until the tower is completed. Note that, as a side effect, the attitudes cause Hector to cover the topface of each of Celia's blocks.

Now, suppose that Hector falsely believes that Celia falsely believes that he intends to cover the top-face of each of her blocks rather than do his bit of their joint performance. Hector thus falsely believes that conditions 3 and 4 in Pettit and Schweikard's account aren't satisfied. This means that Pettit and Schweikard's CK-condition isn't satisfied. This is true even given an undemanding understanding of common knowledge in terms of a 'negatively characterised notion [of] mutual absence of doubt.' [Davies 1987: 717] Such a weak CK-condition requires that the participants each lack false beliefs concerning whether the other conditions hold. But Hector has such a false belief. According to the account, Hector and Celia's joint performance of building the block tower cannot, then, be an intentional joint action.

Note that Hector's false belief can be present and persist while Hector and Celia successfully execute their intentions that they build a block tower (that is, conditions 1-4 can continue to hold true). The false belief can persist without any failure of rationality on the part of either Hector or Celia, even if each is fully aware of their success in each doing what they each intend to do. Hector can attribute to Celia the intention that they enact the pattern of behaviour in which their efforts combine to the effect that a block tower is built while also mistakenly attributing to her the false belief that he just intends to cover each of her blocks. He can do this without thinking that Celia is irrational, since a pattern of behaviour in which their efforts combine to the effect that a block tower is built can in part be formed by Hector's intentional covering of the top-face of each of Celia's blocks. Furthermore, the false belief does not stop Hector from intending that their subplans for building the block tower mesh. Finally, for all we know, Hector's false second-order belief may be justified. His intentions and beliefs may have a perfectly rational etiology. ${ }^{4}$

This kind of case may seem extraordinarily rare. But consider any type of joint activity that can also be performed by a singular individual, such as going for a walk or making a hollandaise sauce. In such a joint activity, one party may falsely believe that the other mistakenly thinks that she herself intends to carry out the activity whether or not the other joins her (so that the satisfaction of the intention is compatible with the other's involvement, but doesn't require it). I may falsely believe that you are under the mistaken impression that I simply intend to go for a walk, rather than that I intend that we go for a walk (that is, what we are supposing that each actually intends). Such false higher-order

\footnotetext{
3 Something akin to Bratman's 'connection condition' is thus satisfied (see [1992: 339]).

${ }^{4}$ Hector will then be in a Gettier situation with respect to his first-order belief about Celia's intention [Gettier 1963]. Note that while it may be that Hector must believe that he will $\varphi$ in order to intend to $\varphi$ (see $\S 3$ ), he need not know that he will.
} 
beliefs are arguably a common upshot of insecurities and mild forms of paranoia that are often present in human relations. And such false higher-order beliefs and doubts can persist throughout joint activities that at least appear to be jointly intentional. But if our walking is jointly intentional only if the CKcondition is satisfied, then such appearances must be illusory. However, in all such cases, agents do not merely each intend to perform individual actions that accidentally have a joint effect. Rather, each intends that they enact the whole action. Due to the interdependence of their intentions, they each settle that they enact the joint performance. Each is thus responsible for bringing it about. Why isn't such a joint performance then an intentional joint action?

\section{The Rational Intending Argument}

The case of Hector and Celia's building of the block tower undermines one possible motivation for the CK-condition, according to which the intentions and beliefs specified by the other conditions will be undermined in the absence of common knowledge (see Tuomela and Miller [1988: 385-87]). According to this Rational Intending Argument (as I call it), the CK-condition is an enabling condition without which the other conditions cannot be satisfied. To illustrate, consider a case where you and I each intend that we walk down to the valley. You intend to do your bit of the walking because I intend to do my bit of it, and I intend to do my bit because you intend to do yours. But suppose that I mistakenly think that you believe that I rather intend that we walk up to the hilltop. If the Rational Intending Argument is sound, then my false belief about your belief about my intention will undermine my intention to do my bit of our walking down to the valley, as well as my intention that we walk there.

The argument rests on the assumption that an agent can intend to $\varphi$ only if she believes that she will $\varphi$. Given this, I can only intend to do my bit of our walking down to the valley if I believe that you will walk down to the valley. After all, if you don't, then I will not be able to do my bit of our walking there. Since I intend to do my bit in part because you intend to do your bit, I must not only believe that you will walk down to the valley, but I must also believe that you intend to walk there (as your bit of our walking there). Furthermore, I realise that you cannot intend to do your bit of our walking down to the valley unless you believe that I will walk down to the valley. Now, I falsely believe that you believe that I intend that we walk up to the hilltop rather than down to the valley, so I will believe that you believe that I will not walk down the valley but rather up to the hilltop. Hence, from my mistaken point of view, you therefore cannot rationally intend that we walk down to the valley, nor intend to do your bit of this walking. This will in turn undermine my own intention. Thus, conditions 1-4 in Pettit and Schweikard's account will not be satisfied.

If my intention would be undermined if I had such a false second-order belief, then your intention would also be undermined if you had a false third-order belief that I had this false second-order belief. My intention would in turn also be undermined if I had a false fourth-order belief that you had such a false thirdorder belief. And so on ad infinitum. Similarly, your intention would be undermined if you had a false second-order belief about my belief concerning 
your intention, and so on ad infinitum. According to the Rational Intending Argument, this shows that participants cannot rationally have the attitudes specified by the other conditions unless it is also common knowledge that they have these attitudes.

The case of Hector and Celia shows that the Rational Intending Argument fails. Hector's intention that he and Celia enact the joint performance of building a block tower is not undermined by his false belief that Celia mistakenly thinks that he merely intends to cover the top-face of each of her blocks.

In addition, we arguably shouldn't accept a strong belief condition on intending. ${ }^{5}$ The Rational Intending Argument won't work with only a weak belief condition on intending, according to which it is sufficient for me to intend to $\varphi$ if I believe that it is possible that I will $\varphi$ (see Kutz [2000: 18]; Ludwig [2007: 387-88]). I could then intend to do my bit of our walking down to the valley in part because you intend to do your bit of this walk, even if I attribute to you the false belief that I rather intend to do my bit of our walking up to the hilltop. After all, you could intend to do your bit of our walking down to the valley because you hope that I will change my mind and start to intend to do my bit of this joint walk.

At one point, Tuomela refers to the Rational Intending Argument as 'the argument for rational and reliable action' [2007: 69, my emphasis]. In a recent paper, Paternotte [2015] argues that a concern for reliability grounds an argument for the necessity of the CK-condition. His starting point is that philosophers take (or should take) an interest in the phenomenon of joint action because the joint actions human beings engage in have an 'intriguing efficiency' [2015: 74]. Hence, '[d] efining joint action consists in pinning down the exact conditions that reliably lead to collective success.' [ibid.] While such an explanatory target certainly makes sense for some purposes, it typically hasn't been the target of philosophical accounts of intentional joint action (but see [Cohen and Levesque 1991: 491]).

It is true that the presence of CK-defeating false higher-order beliefs will typically make coordination of a joint activity somewhat precarious and inflexible. Other things being equal, such false beliefs increase the likelihood of glitches and breakdowns in communication and coordination. However, the importance of efficiency and robustness should not be overstated. Glitches and breakdowns rarely put a complete halt to coordination or communication in joint activity. Typically, they rather merely result in brief temporary obstacles that participants quickly overcome. Indeed, glitches and temporary breakdowns often provide important opportunities for learning [Moore 2013: 492-93].

At any rate, the aim of reductionist accounts is to explicate the difference between intentional joint action and mere coordinated parallel activity. It is not to specify conditions under which joint action is reliably successful. Hence, reductionists cannot appeal to considerations concerning efficiency and reliability in support of the CK-condition.

${ }^{5}$ Bratman rejects a strong belief condition on intending [1987: 37-38]. Tuomela rejects it in later writings [2007: 113]. 


\section{The Partnership Argument}

Pettit and Schweikard preface the introduction of the CK-condition with the following brief motivation:

For all that these clauses [1-4] stipulate, it just might be that you do not believe that I believe that you intend to do your bit, let alone that I intend to do my bit because of believing this; for example, you might regard me, wrongly, as someone who takes you to be acting like a zombie, as if under hypnotic suggestion. And in such a case, there would be reasonable ground for denying that our [joint performance] should count as an unforced, joint action.

[Pettit and Schweikard 2006: 23]

Conditions 2 and 3 are introduced to rule out a similar kind of case, a case in which 'we each thought that others were zombies who would automatically, as if under hypnotism, do what was required of them' [ibid.: 22]. This would be a case in which 'we each thought of ourselves as the only properly intentional agent involved.' [ibid.] Furthermore, the conditions are necessary because in intentional joint action, each must supposedly view themselves as 'on a par with others' and as 'involved on an equal footing in the enterprise of the joint action.' [ibid.: 23] As I put it in $\S 1$, conditions 2 and 3 are supposed to ensure that each treats the others as partners rather than as social tools.

Hector doesn't think that Celia takes him to be acting like a zombie, nor that she thinks that he isn't a properly intentional agent. But arguably, there is a sense in which he doesn't view himself and Celia as proper partners, as 'involved on an equal footing' in their building of the block tower. The underlying idea, I think, is this: Part of what it is for a person $X$ to be person $Y^{\prime}$ 's partner with respect to their J-ing is for $X$ to view $Y$ as his partner with respect to this activity. For instance, if Hector is Celia's partner with respect to their block-tower building, then he must view Celia as his partner with respect to this activity. Furthermore, Hector's viewing Celia as his partner involves viewing her as someone who, in return, views him as a partner. Thus, Hector must view Celia as someone who views him as someone who views her as someone who views him as a partner, and so on and so forth. Viewing another as a partner thus incorporates a kind of intentional reciprocity that is incompatible with the presence of CK-defeating false higherorder beliefs. Nothing but common knowledge of the fact that they have the intentions and beliefs cited in the other conditions is sufficient for the right kind of partnership to be in place.

This Partnership Argument (as I call it) does not merely require that intentionally jointly acting agents treat each other as free intentional agents. It also goes beyond requiring that each is responsible for the whole joint performance, as well as beyond requiring that they each view all of themselves as jointly responsible in this sense. This should make us somewhat suspicious of the claim that a partnership of the kind required by the Partnership Argument is necessary for intentional joint action as such.

More importantly, the Partnership Argument gets the required direction of fit wrong. What should be required is not that each agent views the others as 
partners (mind-to-world), but that each treats the others as partners (world-tomind). This is what is captured by conditions 2 and 3 in Pettit and Schweikard's account, according to which each participant must intend to voluntarily do their bit in part because the others each intend to voluntarily do their bits. Bratman captures this requirement with the condition that each must intend that they J 'in accordance with and because of the others' intentions that they J and that each must intend that they do this by way of meshing sub-plans. Now, treating someone as a partner is perfectly consistent with viewing her as someone who doesn't treat or view you as a partner. Even if Hector thinks that Celia neither treats or views him as a proper partner with respect to their building of the block tower, he can still treat her as a partner. Indeed, treating someone as a partner is often an effective way of getting him or her to start treating you as a partner in return.

Still, one might think that Pettit and Schweikard's conditions 2 and 3-or Bratman's demand for interlocking intentions and intended mesh-don't adequately capture what it is to treat someone as a proper partner. After all, even if Hector intends to do his bit because Celia intends to do her bit, he may intend to keep her in the dark about what his intention is. He may intend that she continues to believe what he mistakenly thinks she believes, namely that he intends to merely cover the top-face of her blocks. While Hector's intention that their sub-plans mesh puts some rational pressure on him to make his intention and sub-plans manifest to Celia, he could still rationally have this deceptive intention. Perhaps Celia is usually a teaser, so Hector mistakenly thinks that she wouldn't intend that they build a block tower if she knew that this is what he also intended.

However, note that the CK-condition doesn't rule out this kind of deceptive intent. What is needed to rule out deceptive intent is a negatively characterised requirement like the following: 6

$5^{\prime}$. they each do not intend that the others be deceived about whether the other clauses hold.

Condition $5^{\prime}$ could be satisfied even in the presence of CK-defeating false higherorder beliefs, and the CK-condition could be satisfied even if $5^{\prime}$ were not satisfied. A concern with ensuring that each participant treats the others as partners thus fails to support the CK-condition. ${ }^{7}$

\footnotetext{
${ }^{6}$ For a similar point regarding the conditions for communicative intent, see Grice [1969: 159].

${ }^{7}$ However, without the CK-condition, Pettit and Schweikard's account doesn't rule out cases where participants falsely believe that there is no single joint performance that they each intend that they enact (and thus, where they fail to realise that condition 1 is satisfied). In such cases, participants arguably view themselves as involved in a kind of mutual exploitation rather than intentional cooperation. The CK-condition is not necessary for ruling out these cases though; a condition that requires each to believe or assume that there is such a single
} 


\section{The Agential Knowledge Argument}

Despite the failure of the arguments I have considered, the CK-condition nevertheless remains compelling. If Hector and Celia's block-tower building is an intentional joint action, then Hector will be participating in an intentional joint action even if his participation in it, qua intentional joint action, will be unintentional. Intuitively, one might think that to participate in a joint intentional action, one must intentionally participate in it qua intentional joint action. This requires that one knows, at the very least, that one is trying to participate in the intentional joint action. Perhaps an appeal to such an agential knowledge that is constitutive of intentional joint action could ground an argument for the CKcondition.

The thought here, inspired by Anscombe [1957], is that there is a special sense of the question 'Why?' that applies to an agent's participation in a intentional joint action (see Laurence [2011]; Schmid [forthcoming]). In an intentional joint action, each participant's bit is rationalised by the joint action that it is supposed to contribute to and be part of. 'Hector, why are you putting your block on top of Celia's?', we might ask. If their activity were jointly intentional, then Hector could respond: 'I'm putting it there because we are building a block tower together.' Arguably, he wouldn't intentionally participate in their joint activity of building the block tower (which wouldn't then be jointly intentional) unless he knew-in a 'non-observational' way-that this is what they were at least trying to do. But Hector's false second-order belief seems to undermine such agential knowledge, and thus, their activity's status as an intentional joint action. To rule out all such agential knowledge-undermining false higher-order beliefs, the CK-condition must be introduced. Or so the argument would go.

Of course, common knowledge is not non-observational in the way that agential knowledge allegedly is. If participants have agential knowledge of their intentional joint action, then it must arguably be based on each participant's own grasp of the content of an intention (see, e.g. Velleman [2007]). The thought then, is that the CK-condition plays an enabling role in giving each participant this grasp. But in virtue of which intention could Hector have this agential knowledge? Presumably, either the shared intention in which he partakes or his personal intention that they build the block tower. Unfortunately, a reductionist cannot construct an argument for the CK-condition on the basis of either.

Consider first the agential knowledge provided by Hector's personal intention. Recall that the notion of a joint performance isn't the notion of an intentional joint action. Since neither Hector nor Celia intends to participate in an intentional joint action, neither needs the agential knowledge that they are trying to participate in an intentional joint action. When Hector responds to our question 'Why?', his answer-enabled by his grasp of the content of his personal intentions-should be interpreted as 'I'm putting it there because we are enacting a pattern of behaviour in which our efforts combine to the effect that

joint performance suffices (see Blomberg [forthcoming] for an in-depth discussion). 
the block tower is built.' His false second-order belief does not undermine the knowledge he expresses with this answer.

A more promising basis for the relevant kind of agential knowledge might be the shared intention itself. Bratman [1993] frequently uses the locution 'our shared intention to J' even though the participants' intentions have the content 'that we J'. This may suggest, misleadingly, that there is an object of the shared intention (a performance) that is different from the object of the participants' intentions (a state of affairs). Each participant must then have a grasp of a content that is different from that of his or her own personal intention. The CK-condition would then be needed, one might think, to ensure such a grasp. It is not sufficient to merely add a necessary condition $5^{*}$ that each believes that conditions $1-4$ hold. Each could then believe that $5^{*}$ didn't hold (and hence, each could believe that they didn't have their shared intention). Adding a condition 6 that rules this out won't help, since each could then believe that 6 didn't hold. And so on ad infinitum. Nothing but common knowledge is sufficient for providing participants with the right kind of awareness of their shared intention to J.

However, this argument is unavailable to reductionists. They reject that intentionally jointly acting individuals need to jointly form a literal state of intention that belongs to each and all of them. 'Shared intention' is a technical term that refers to a structure of ordinary individual propositional attitudes, so there is no shared intention 'to J' for participants to grasp (see Bratman [1993: 98-99]; Pettit and Schweikard [2006: 30]). Hence, the reductionist cannot rest an argument for the CK-condition on considerations concerning agential knowledge of the shared intention or of the participants' personal intentions. ${ }^{8}$

Perhaps this is too quick. Ought not the interpersonal structure of shared intention play a role in shared agency that is analogous to the role that intention plays in individual agency? If so, then the structure should arguably provide participants with knowledge of the structure itself, in the way that an individual's intention provides her with knowledge of what she is intending. This may be the reasoning behind Alonso's claim that '[i]t is reasonable to think that if we have a shared intention to, say, dance the tango, each of us must be in a position to plan and act on the commonly known assumption that we have a shared intention to dance the tango.' [2009: 458] But insofar as shared intention simply is a structure of attitudes that distinguishes intentional joint action from parallel action, this requirement is too strong. The participants' bilateral coordination of their plans and actions need not itself be commonly known, but may rather emerge out of their interlocking intentions and intended meshing of subplans. Other things being equal, these intentions will put rational pressure on the participants to make their intentions manifest to each other. This will tend to eliminate higher-order false beliefs and create conditions for common

\footnotetext{
${ }^{8}$ If a kind of plural agential knowledge of our intentional joint action is nevertheless constitutive of it being jointly intentional, then the reductionist accounts are really eliminativist accounts. As Schmid [forthcoming] puts it, the upshot of the reductionist approach would be that 'what groups can do is really more like an emulation of one token intentional action that individuals can pull off if they combine in a suitable manner.'
} 
knowledge. Hence, structures of shared intention can help explain the prevalence of common knowledge in human groups, but the CK-condition is not necessary for explaining intentional joint action.

\section{Conclusion}

In light of my review of three arguments for the CK-condition, reductionists about intentional joint action should reject a necessary CK-condition. The presence of false CK-defeating higher-order beliefs is compatible with joint responsibility as well as with participants treating each others as partners rather than social tools. Of course, this does not mean that the best explanation of why people persist in having the concordant intentions and expectations required for intentional joint action isn't often that the CK-condition is satisfied. Nor does it mean that common knowledge doesn't facilitate robustness, efficiency and flexibility in our joint endeavours. Finally, it doesn't mean that common knowledge isn't necessary for two agents to launch a rationally coordinated joint attack in circumstances where failure of coordination is very costly (see Chant and Ernst [2008: 552-56]). None of this, however, shows that the CK-condition is necessary for intentional joint action as such. ${ }^{9}$

\section{References}

Alonso, Facundo 2009. Shared Intention, Reliance, and Interpersonal Obligations, Ethics 119/3: 444-75.

Anscombe, Elizabeth 1957. Intention, Oxford: Basil Blackwell.

Blomberg, Olle [forthcoming]. Shared Intention and the Doxastic Single End Condition, Philosophical Studies.

Bratman, Michael 1987. Intention, Plans, and Practical Reason, Cambridge: Harvard University Press.

Bratman, Michael 1992. Shared Cooperative Activity, The Philosophical Review 101/2: 327-41.

Bratman, Michael 1993. Shared Intention, Ethics 104/1: 97-113.

\footnotetext{
${ }^{9}$ Acknowledgements: For helpful discussions and comments at various stages, thanks to Steve Butterfill, Suilin Lavelle, Piotr Makowski, John Michael, Richard Moore, Matt Nudds, Björn Petersson, Glenda Satne, Hans Bernhard Schmid, David Schweikard and Michael Wilby. I have also benefited from comments from participants at conferences and seminars in Antwerp, Berlin, Edinburgh, Helsinki, Leipzig, Paris, Stockholm, Stuttgart and Vienna. Finally, I'm grateful for comments from this journal's editor and two anonymous referees, as well as for comments from two referees for Synthese on an earlier, very different, version of this paper. My work on this paper was supported by a postdoctoral research grant (DFF-4089-00091) from the Danish Council for Independent Research and FP7 Marie Curie Actions COFUND under the 7th EU Framework Programme.
} 
Bratman, Michael 1997a. I Intend That We J, in Contemporary Action Theory Volume 2: Social Action, ed. by Ghita Holmström-Hintikka and Raimo Tuomela, Dordrecht: Kluwer Academic Publishers: 49-63.

Bratman, Michael 1997b. Responsibility and Planning, The Journal of Ethics 1/1: 27-43.

Bratman, Michael 2014. Shared Agency: A Planning Theory of Acting Together, New York: Oxford University Press.

Chant, Sara Rachel and Zachery Ernst 2008. Epistemic Conditions for Collective Action, Mind 117/467: 549-73.

Cohen, Philip R. and Hector J. Levesque 1991. Teamwork, Noûs 25/4: 487-512.

Davies, Martin 1987. Relevance and Mutual Knowledge, Behavioral and Brain Sciences 10/4: 716-17.

Gettier, Edmund L. 1963. Is Justified True Belief Knowledge?, Analysis 23/6: 12123.

Grice, Paul 1969. Utterer's Meaning and Intention, The Philosophical Review 78/2: 147-77.

Kutz, Christopher 2000. Acting Together, Philosophy and Phenomenological Research 61/1: 1-31.

Laurence, Ben 2011. An Anscombian Approach to Collective Action, in Essays on Anscombe's Intention, ed. Anton Ford, Jennifer Hornsby and Frederick Stoutland, Cambridge: Harvard University Press: 270-94.

Lewis, David K 1969. Convention, Cambridge: Harvard University Press.

Ludwig, Kirk 2007. Collective Intentional Behavior from the Standpoint of Semantics, Noûs 41/3: 355-93.

Miller, Seumas 2001. Social Action: A Teleological Account, Cambridge: Cambridge University Press.

Moore, Richard 2013. Imitation and Conventional Communication, Biology and Philosophy 28/3: 481-500.

Paternotte, Cedric 2015. The Epistemic Core of Weak Joint Action, Philosophical Psychology 28/1: 70-93.

Pettit, Philip and David Schweikard 2006. Joint Actions and Group Agents, Philosophy of the Social Sciences 36/1: 18-39.

Schmid, Hans Bernard [forthcoming]. On Knowing What We're Doing Together: Groundless Group Self-Knowledge and Plural Self-Blindness, in The Epistemic Life of Groups, ed. Miranda Fricker and Michael Brady, Oxford: Oxford University Press.

Sverdlik, Steven 1987. Collective Responsibility, Philosophical Studies 51/1: 6176. 
Tollefsen, Deborah 2005. Let's Pretend! Children and Joint Action, Philosophy of the Social Sciences 35/1: 75-97.

Tuomela, Raimo 2007. The Philosophy of Sociality: The Shared Point of View, New York: Oxford University Press.

Tuomela, Raimo and Kaarlo Miller 1988. We-Intentions, Philosophical Studies 53/3: 367-89.

Velleman, J. David 2007. What Good Is a Will?, in Action in Context, ed. Anton Leist, Berlin: Walter de Gruyter: 193-215. 